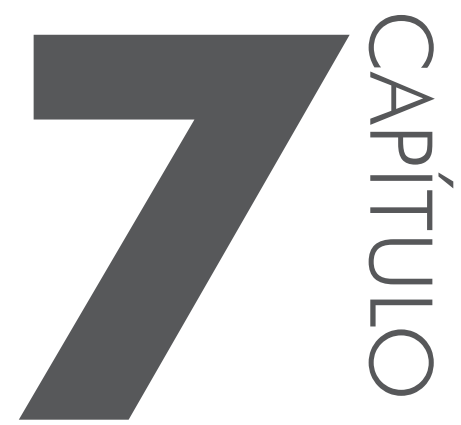

\title{
POLIITICA NACIONAL DOS RESÍDUOS SÓLIDOS: DIAGNÓSTICO DO GERENCIAMENTO NO MUNICÍPIO DE GOIANDIRA-GO
}

Mayara Cristina Tristão Estevane de Paula Pontes Mendes Thiago Patricinio Silva

Resumo: O presente trabalho busca verificar a vigência das legislações pertinentes à Política Nacional de Resíduos Sólidos no município de Goiandira, Goiás e identificar e caracterizar o manejo e a gestão dos resíduos urbanos produzidos neste Município. A pesquisa foi realizada nos meses de janeiro e fevereiro de 
2015, e contou com a participação de em média dez voluntários. Para obtenção de dados referentes à geração e caracterização dos resíduos, foram estipuladas três amostragens. Após a coleta, esse material foi destinado ao Aterro Sanitário de Catalão, onde se utilizou das estruturas físicas para pesagem e triagem. De acordo com os resultados obtidos, concluímos que Goiandira faz parte do Rol nacional de municípios que não atendem às conformidades estabelecidas pela Política Nacional de Resíduos Sólidos. O cenário atual dos aspectos administrativos, operacionais e estruturais da prestação de serviços retratados pelo diagnóstico situacional, alcançou níveis pouco satisfatórios na maioria de seus indicadores, o que revela carências e deficiências, cuja superação deve ser objeto de implantação de programas que possam minimizar os impactos socioambientais.

Palavras-chave: Política Nacional de Resíduos Sólidos. Gestão de Resíduos Sólidos. Lei n ${ }^{\circ}$ 12.305/2010.

Abstract: This study aims to verify the validity of the relevant legislation the National Policy on Solid Waste in the municipality of Goiandira, Goiás. We sought to identify and characterize the handling and management of municipal waste produced in this city. The survey was conducted in January and February 2015 and was attended to on average 10 volunteers. To obtain data on the generation and characterization of waste, three samples were stipulated. After collection, the material was destined for landfill Catalan Health, where he used the physical structures for weighing and sorting. According to the results we conclude that Goiandira part of the national Roll of municipalities that do not meet compliance established by the National Policy on Solid Waste. The current scenario of administrative, operational and structural service delivery portrayed by situational diagnosis, achieved unsatisfactory levels in most of the indicators, which shows shortcomings and deficiencies, the overshoot should be programs implementation object that can minimize impacts social and environmental.

Keywords: National Policy on Solid Waste. Solid Waste Management. Law $\mathrm{n}^{\mathrm{o}} 12.305 / 2010$.

\section{INTRODUC̣ÃO}

A questão ambiental nunca foi tão discutida como nos dias atuais, porém, ocorre sem critérios específicos e, o pior, sem práticas que de fato interfiram na qualidade de nossa vida e do ambiente em que vivemos. Vale ressaltar que a reflexão ambiental deve ser feita em paralelo com a questão social e com as relações capitalistas de exploração e degradação. Outro fator que merece destaque, na questão socioambiental, é o consumismo exacerbado, que tomou conta do Brasil e do mundo. Esse consumismo é a força motriz do sistema capitalista e traz junto consequências desastrosas ao ambiente, como o excesso de lixo, que, por conse- 
guinte, causa, por exemplo, enchentes nos grandes centros. Os resíduos sólidos, popularmente conhecidos como lixo, são definidos pelo Ministério do Meio Ambiente, por meio do Plano Nacional de Resíduos Sólidos, como:

\begin{abstract}
Material, substância, objeto ou bem descartado resultante de atividades humanas em sociedade, cuja destinação final procede, se propõe proceder ou se está obrigado a proceder, nos estados sólido ou semissólido, bem como gases contidos em recipientes e líquidos cujas particularidades tornem inviável o seu lançamento na rede pública de esgotos ou em corpos d'água, ou exijam para isso soluções técnicas ou economicamente inviáveis em face da melhor tecnologia disponível (BRASIL, 2010, p. 1).
\end{abstract}

De acordo com Ojima (2007), o crescimento da população urbana está diretamente ligado ao crescimento do consumo, e, por consequência, ao aumento do uso de matérias-primas e à geração de resíduos. Hoje, o progresso significa produzir mais, induzindo, assim, a um consumo cada vez maior de bens materiais, que, ligados a conceitos de praticidade e facilidade, levaram à mentalidade do descartável. Porto-Gonçalves (2006) aponta que, em nome do desenvolvimento e de "melhores" condições de vida, foi aceita a ideia de que a degradação ambiental é o preço que se paga pelo progresso, tão necessário ao ideal de globalização imposto pelo capitalismo.

Segundo Pesquisa Nacional de Saneamento Básico (PNSB), realizada pelo IBGE em 2000, são coletados atualmente no Brasil cerca de 228.413 toneladas de resíduos sólidos por dia, sendo que $52,5 \%$ destes constitui-se de matéria orgânica (D’ALMEIDA; VILHENA, 2000). As quantidades de resíduos gerados pelos brasileiros vêm aumentando anualmente, e, variam, segundo a mesma pesquisa, nas cidades com até 200 mil habitantes, de 450 a 700 gramas por pessoa. Já nas cidades com mais de 200 mil habitantes, essa quantidade aumenta para a faixa entre 800 e 1.200 gramas por habitante/dia.

O modo de produção do resíduo e suas características se modificam continuamente como consequência do desenvolvimento tecnológico e econômico. Um dos principais instrumentos da Política Nacional é o Plano Nacional de Resíduos Sólidos (PNRS) é estabelecer diretrizes e metas para a gestão dos resíduos sólidos no Brasil. Outra meta é o aumento da vida útil dos aterros, o que acrescenta o reuso e a reciclagem dos produtos.

O manejo dos resíduos sólidos consiste em um conjunto de atividades, infraestruturas e instalações operacionais de coleta, transporte, transbordo, tratamento e destinação final dos resíduos de origem doméstica, originários da varrição, da limpeza de logradouros e das vias públicas. É dever do Município gerenciar os resíduos sólidos produzidos pela sua população e se adequar no prazo previsto a Lei $n^{\circ} 12.305 / 2010$ que estabelece a eliminação dos lixões nos municípios. 
Contudo, em grande parte dos municípios brasileiros, principalmente naqueles considerados de pequeno porte, com população de até 20.000 habitantes, a disposição inadequada de resíduos sólidos é um problema visível. Vale salientar que a questão da redução desses resíduos e sua destinação final devem envolver, além da participação do governo, a iniciativa privada e a sociedade civil organizada, levando em conta as características dos municípios, como sua estrutura organizacional, conscientização da população e previsões orçamentárias (ZANTA; FERREIRA, 2003).

Nesse sentido, torna-se relevante a análise da gestão integrada dos resíduos sólidos municipais, entendendo a necessidade de implantação de técnicas de gerenciamento dos diferentes resíduos e a participação efetiva da comunidade no controle e na geração desses resíduos. Essas medidas podem assegurar a redução significativa dos níveis de poluição ambiental, do desperdício de recursos naturais, por meio da economia de energia e de matérias-primas.

\section{CLASSIFICAC̣ÃO DOS RESÍDUOS}

A palavra lixo deriva do termo latim lix, que significa cinza, e segundo dicionário (Michaelis,1987) é definida como sujeira, imundice, escória. Na linguagem técnica é sinônimo de resíduos sólidos e é representado por materiais descartados pelas atividades humanas, os quais podem ser reciclados e parcialmente utilizados, tendo entre outros benefícios, proteção à saúde pública, economia de recursos naturais.

Em decorrência das mudanças tecnológicas mundiais e da conscientização da necessidade de reaproveitamento desses resíduos, estes materiais passaram a ser vistos com um valor econômico agregado, tornando-se fonte de renda e atividade social acolhedora (BAASCH, 1995).

Em função da origem, os resíduos sólidos podem ser classificados, segundo o Instituto de Pesquisas Tecnológicas (2000), em:

a) Domiciliares: gerados nas residências e constituídos por restos de alimentos, materiais potencialmente recicláveis, como metal, plástico, vidro, papéis em geral, além de lixo sanitário e tóxico;

b) Comerciais: provenientes das atividades comerciais e de serviços, tais como supermercados, bancos, lojas, bares e restaurantes;

c) Públicos: originados dos serviços de limpeza pública urbana, tais como varrição de vias, praias, galerias, córregos e restos de podas de árvores e áreas de feiras livres;

d) Serviços de Saúde e Hospitalar: constituem-se em resíduos sépticos como agulhas, seringas, gazes, órgãos e tecidos removidos, luvas, remédios com validade vencida e materiais de raio-X; 
e) Industriais: variam conforme a atividade da indústria, incluindo nesta categoria a grande maioria do lixo considerado tóxico;

f) Agrícolas: resultados das atividades de agropecuária, contêm embalagens de fertilizantes e defensivos agrícolas geralmente tóxicos;

g) Entulhos: resíduos da construção civil, como materiais de demolição e restos de obras.

Em função da periculosidade dos resíduos, os mesmos podem ser classificados segundo a Norma ${ }^{\circ} 10.004$ - ABNT 2004, em três categorias:

h) Classe I - perigosos, pois apresentam riscos à saúde e ao ambiente visto que apresentam certas propriedades, tais como corrosividade, inflamabilidade, reatividade, toxidade e patogenicidade;

i) Classe II - resíduos não inertes, que não se enquadram nas classes I e III, mas que podem conter propriedades como combustibilidade, biodegradabilidade ou solubilidade em água;

j) Classe III - resíduos inertes, cujos constituintes solubilizados não possuem concentração inferior ao padrão de potabilidade de água.

\section{LEGISLAC̣ÕES PERTINENTES}

Atualmente, o Brasil conta com um arcabouço legal que estabelece diretrizes para a gestão dos resíduos sólidos por meio da Política Nacional de Resíduos Sólidos (Lei n ${ }^{\circ} 12.305 / 2010$ ), e para a prestação dos serviços públicos de limpeza urbana e manejo de resíduos sólidos por meio da Lei Federal de Saneamento Básico (Lei n ${ }^{\circ}$ 11.445/2007). Também conta, desde 2005, com a Lei de Consórcios Públicos (Lei n $\left.{ }^{\circ} 11.107 / 2005\right)$ que permite estabilizar relações de cooperação federativa para a prestação desses serviços.

A Constituição Federal, promulgada em 1988, estabelece em seu artigo 23, inciso VI, que "compete à União, aos Estados, ao Distrito Federal e aos Municípios proteger o meio ambiente e combater a poluição em qualquer das suas formas". O artigo 24 estabelece a competência da União, dos Estados e do Distrito Federal em legislar concorrentemente sobre “(...) proteção do meio ambiente e controle da poluição" (inciso VI) e, o artigo 30, incisos I e II, estabelece que cabe ainda ao poder público municipal "legislar sobre os assuntos de interesse local e suplementar a legislação federal e a estadual no que couber" (BRASIL, 1988).

A Lei 12.305, de 02 de agosto de 2010, instituiu a Política Nacional de Resíduos Sólidos dispõe sobre os princípios, objetivos, instrumentos e diretrizes relativos à gestão integrada e ao gerenciamento de resíduos sólidos, incluindo os perigosos, à exceção dos rejeitos radioativos, objeto de regulação especifica, e delimita a esfera de responsabilidade dos geradores de resíduos e do poder público, além de prever instrumentos econômicos (BRASIL, 2010). 
Essa lei estrutura-se de forma a se integrar à Lei 11.445/2007 (Política Federal de Saneamento Básico), razão pela qual possui formatação um pouco diferente. A afirmativa evidencia-se logo no início do diploma, uma vez que seus arts. $2^{\circ}$. e $5^{\circ}$. fazem expressa referência a Lei 11.445/2007.

Art. $2^{\circ}$ Aplicam-se aos resíduos sólidos, além do disposto nesta Lei, nas Leis nos 11.445, de 5 de janeiro de 2007, 9.974, de 6 de junho de 2000, e 9.966, de 28 de abril de 2000, as normas estabelecidas pelos órgãos do Sistema Nacional do Meio Ambiente (Sisnama), do Sistema Nacional de Vigilância Sanitária (SNVS), do Sistema Unificado de Atenção à Sanidade Agropecuária (Suasa) e do Sistema Nacional de Metrologia, Normalização e Qualidade Industrial (Sinmetro) (Brasil, 2007).

Art. 5 $5^{\circ}$ A Política Nacional de Resíduos Sólidos integra a Política Nacional do Meio Ambiente e articula-se com a Política Nacional de Educação Ambiental, regulada pela Lei n ${ }^{\circ}$ 9.795, de 27 de abril de 1999, com a Política Federal de Saneamento Básico, regulada pela Lei $\mathrm{n}^{\circ} 11.445$, de 2007, e com a Lei ${ }^{\circ} 11.107$, de 6 de abril de 2005 (Brasil, 2007).

Ainda sobre a Lei $\mathrm{n}^{\circ} 12.305 / 2010$, esta impõe a todos a responsabilidade de dar efetividade à destinação correta dos resíduos gerados, bem como determina prazo para o fechamento dos lixões ativos no país, conforme transcrito no art. 54. o qual menciona que "a disposição final ambientalmente adequada dos rejeitos, observado o disposto no $\mathbb{S} 1$ o do art. $9^{\circ}$, deverá ser implantada em até 4 (quatro) anos após a data de publicação desta Lei” (BRASIL, 2010).

Já a lei n ${ }^{\circ} 14.248$, de 29 de julho de 2002, que dispõe sobre a Política Estadual de Resíduos Sólidos do estado de Goiás define diretrizes e normas de prevenção da poluição, promove padrões sustentáveis de produção e consumo, e também promove o gerenciamento integrado por meio da articulação entre o Poder Público, os produtores e demais segmentos da sociedade civil.

A seguir são apresentadas outras legislações federais pertinentes à limpeza urbana e manejo dos resíduos sólidos:

1) Resolução CONAMA n ${ }^{\circ}$ 005, de 31 de março de 1993 - Dispõe sobre o tratamento de resíduos gerados em estabelecimentos de saúde, portos e aeroportos e terminais ferroviários e rodoviários.

2) Lei ordinária $n^{\circ}$ 787, de 1997 - Dispõe sobre o Programa de Prevenção de Contaminação por Resíduos Tóxicos, a ser promovido por empresas fabricantes de lâmpadas fluorescentes de vapor de mercúrio, de vapor de sódio e de luz mista e dá outras providências.

3) Resolução CONAMA n ${ }^{\circ}$ 237, de 19 de dezembro de 1997 - Estabelece norma geral sobre licenciamento ambiental, competências, listas de atividades sujeitas a licenciamento etc. 
4) Resolução CONAMA no 257, de 30 de junho de 1999 - Define critérios de gerenciamento para destinação final ambientalmente adequada de pilhas e baterias.

5) Resolução CONAMA n ${ }^{\circ}$ 27, de 27 de junho de 2001 - Estabelece o novo código de cores para os diferentes tipos de resíduos;

6) Resolução CONAMA n ${ }^{\circ}$ 307, de 5 de julho de 2002 - Estabelece diretrizes, critérios e procedimentos para a gestão dos resíduos da construção civil;

7) Resolução CONAMA n ${ }^{\circ} 358$, de 29 de abril de 2005 - Dispõe sobre o tratamento e a disposição final dos resíduos dos serviços de saúde e dá outras providências.

Da normalização técnica da Associação Brasileira de Normas Técnicas (ABNT) são citadas somente algumas mais específicas ao tema tratado:

- NBR 7039, de 1987 - Pilhas e acumuladores elétricos - Terminologia.

- NBR 7501, de 1989 - Transporte de produtos perigosos - Terminologia.

- NBR 11174, de 1990 - Armazenamento de resíduos classe II-A, não-inertes, e classe II-B, inertes - Procedimentos.

- NBR 8419, de 1992 - Apresentação de projetos de aterros sanitários de resíduos sólidos urbanos.

- NBR 12245, de 1992 - Armazenamento de resíduos sólidos perigosos Procedimentos.

- NBR 12807, de 1993 - Resíduos de serviço de saúde - Terminologia.

- NBR 12808, de 1993 - Resíduos de serviço de saúde - Classificação.

- NBR 13221, de 1994 - Transporte de resíduos - Procedimento.

- NBR 13.221, de 2003 - Transporte terrestre de resíduos;

- NBR 10004, de 2004 - Resíduos sólidos - Classificação.

De acordo com a Constituição Brasileira é competência comum da União, dos Estados, do Distrito Federal e dos Municípios proteger o meio ambiente e combater a poluição, além de promover programas de saneamento básico. $\mathrm{O}$ estado de Goiás possui atualmente 246 municípios, divididos nas dez regiões de planejamento adotadas pela Secretaria de Planejamento (SEPLAN). Estas regiões possuem características sociais, econômicas, culturais e políticas semelhantes. Segundo o IBGE (2010), o estado de Goiás possui 90,29\% de sua população concentrada em áreas urbanas. Este cenário aponta para vários problemas relacionados à ausência de saneamento básico, de infraestrutura mínima de moradia e de acessibilidade.

Em 2004 e 2005, a Agência Ambiental de Goiás realizou o primeiro diagnóstico da disposição do lixo urbano nos municípios goianos. Naquela oportunida- 
de, ficou demonstrada que a maioria dos municípios goianos $(74,8 \%)$ realizava disposição do lixo urbano na condição de lixão, 21,95\% executava a disposição de maneira menos inconveniente, em projetos que operavam na condição de aterro controlado, e somente $3,25 \%$, em aterro sanitário.

Nessa pesquisa também ficou evidenciada a fragilidade das políticas públicas voltadas às questões do saneamento ambiental urbano. Notadamente no caso dos municípios de pequeno porte, que poderão tornar-se relevante para as questões ambientais e de saúde pública, se não houver a presença atuante e decisiva do governo federal, estadual e municipal, no âmbito de suas competências (FERREIRA, 2006).

\section{OS CAMINHOS DA PESQUISA}

Dentro de qualquer projeto que vise equacionar o problema dos resíduos sólidos urbanos de uma comunidade, tem-se, como primeira etapa de trabalho, a determinação qualitativa e quantitativa dos resíduos. Este conhecimento é fundamental tanto para o dimensionamento dos sistemas de coleta e transporte quanto para o fornecimento de elementos indispensáveis na escolha do sistema de tratamento e destinação. Para definir resíduo sólido, foi observada a NBR 10.004:2004 que salienta:

Resíduos nos estados sólido e semi-sólido, que resultam de atividades de origem industrial, doméstica, hospitalar, comercial, agrícola, de serviços e de varrição. Ficam incluídos nesta definição os lodos provenientes de sistemas de tratamento de água, aqueles gerados em equipamentos e instalações de controle de poluição, bem como determinados líquidos cujas particularidades tornem inviável o seu lançamento na rede pública de esgotos ou corpos de água, ou exijam para isso soluções técnicas e economicamente inviáveis, em face à melhor tecnologia disponível (ABNT, 2004).

Essa pesquisa desenvolvida no município de Goiandira-GO, juntamente com o apoio da Secretaria Municipal de Meio Ambiente, contou com a disposição de em média dez colaboradores envolvidos em diferentes etapas descritas logo abaixo.

\subsection{Caracterização do município}

O município de Goiandira está disposto nos limites do Estado de Goiás, inserido no bioma Cerrado e apresenta relevo suavemente ondulado, sem grandes áreas aplainadas, com altitudes variando entre 520 e 880 metros. Segundo o IBGE (2014), a área do município é de $564,687 \mathrm{~km}^{2}$. Regionalmente, Goiandira está inserida na bacia hidrográfica do Paranaíba e localmente na sub-bacia do Rio Veríssimo, sendo que estas redes de bacias pertencem a uma classificação mais ampla, em que o município encontra-se dentro da Região Hidrográfica do Rio Paraná (ANA, 2011). 
O curso d'água de expressão dentro do município é o Rio Veríssimo, sendo que a cidade também é circundada pelos Córregos Água Fria, Lageado, Campo Limpo, Matinha e Catingueiro. O Centro Tecnológico de Engenharia (CTE, 2006) e o Sistema Naturae - Consultoria Ambiental Ltda. (2006), em análises realizadas para compor o Estudo Integrado da bacia hidrográfica do rio Veríssimo, evidenciaram que o clima tropical regional é definido por duas estações bem definidas, um período seco e um período chuvoso. No período chuvoso a precipitação mensal é superior a $200 \mathrm{~mm}$ (52\% do total de precipitação anual).

A bacia do rio Veríssimo possui uma área de $4.533,7 \mathrm{~km}^{2}$, localiza-se na região Sul do estado de Goiás, abrange os municípios de Corumbaíba, Anhanguera, Cumari, Goiandira, Nova Aurora, Catalão, Ipameri e Campo Alegre de Goiás. A formação vegetacional é esparsa, com fortes evidências de antropização sobre as Matas Ciliares, Matas de Galerias, Veredas, dentre outras.

De acordo com dados do IBGE (2014), a economia do município baseia-se em agricultura, pecuária, comércio e indústria, mas a pecuária é a atividade que predomina no município. Sendo que o maior rebanho é o de bovinos, principalmente as vacas de ordenha. Já na agricultura, a principal produção do município são lavouras de milho e soja. Em escala comercial ou para o consumo, podem se alinhar, entre outros, produtos da terra, como o feijão, o café, a mandioca, as hortaliças e frutas como banana, maracujá e manga. Com relação às indústrias, os principais seguimentos são: laticínio, cerâmica, cerealista, fabricação de lajotas, fabrica de ração e há também as pequenas empresas que ainda não possuem regularização.

\subsection{Análise observacional do aterro municipal e coleta de dados}

Atualmente, o aterro municipal encontra-se disposto a cerca de $2 \mathrm{~km}$ do perímetro urbano, na rodovia Goiandira/Catalão (GO-210), é administrado pela Prefeitura Municipal e conta apenas com um funcionário autônomo, responsável pelo manejo de todo material ali disposto e sua destinação. Para a coleta de dados, utilizou-se o método de análise observacional in loco, onde foram realizadas visitas semanais entre os meses de janeiro e fevereiro de 2015. Nesta fase, itens como infraestrutura, normatização, disposição final dos resíduos, controle interno, dentre outros, foram observados e descritos.

Acondicionar os resíduos sólidos domiciliares significa prepará-los para a coleta de forma adequada, bem como agregar valor a estes produtos que servirão de mercadoria posteriormente. Durante essa etapa, foi necessário trilhar a cidade e identificar as várias formas de acondicionamento utilizadas pelos moradores do município. Esse levantamento foi realizado entre os dias 12 e 16 de janeiro de 2015. Durante esses cinco dias, foram percorridas todas as vias públicas do município, e, com o auxílio de caneta e prancheta, anotados todos os dados necessários. 
Com a finalidade de reunir dados quanto à coleta e ao transporte do material foi realizado um acompanhamento com os funcionários da Prefeitura $\mathrm{Mu}$ nicipal durante a realização de suas atividades de coleta, por um período de 30 dias. Esse acompanhamento foi desenvolvido no decorrer do mês de janeiro de 2015. Para caracterizar o material, houve uma parceria entre a Prefeitura $\mathrm{Mu}$ nicipal de Goiandira e a Prefeitura Municipal de Catalão, cidade vizinha, cuja Secretaria de Meio Ambiente de Catalão, disponibilizou todas as estruturas físicas de seu Aterro Sanitário como balança, esteira, galpão, dentre outros para o levantamento de dados. Essa parceria se fez necessária pela falta de infraestrutura no Aterro em Goiandira.

Em relação à coleta de dados quantitativos foram estipuladas três amostragens que ocorreram nos dias 02/02/15, segunda feira; 04/02/15, quarta feira; $06 / 02 / 15$, sexta feira, iniciadas às $5 \mathrm{~h} 30$, realizadas voluntariamente pelos funcionários responsáveis pela coleta de lixo regular. Após o término das atividades, esses resíduos foram destinados para Catalão no próprio veículo coletor. Ao chegar ao Aterro, foram pesados em balança específica e encaminhados ao galpão de triagem para a devida separação. Logo em seguida, com a ajuda dos trabalhadores da Cooperativa de Reciclagem, esses resíduos passaram pela triagem.

Durante a triagem, esse material foi separado e categorizado de acordo com as subdivisões que a própria cooperativa trabalha: Garrafa Pet; Plástico; Metal/ Sucata; Papelão; Caixa de leite; Pneus; Orgânicos/Final de esteira. Todos os itens foram induzidos a sacolões específicos e posteriormente pesados. Assim, após a caracterização, esse material foi destinado à cooperativa para respectiva venda. Já o material analisado como orgânico e de final da esteira foram devidamente encaminhados para a trincheira e aterrados.

\section{RESULTADOS E DISCUSSÃO}

Após análise minuciosa, evidenciamos que o município de Goiandira não difere dos demais municípios brasileiros, considerados de pequeno porte na produção de resíduos. A população goiandirense origina resíduos domésticos oriundos da vida diária nas residências existentes no município, constituídos por restos de alimentos, jornais, embalagens, dentre outros, necessários à vida cotidiana.

Os resíduos comerciais também são provindos das atividades de prestação de serviços e comércio desenvolvidas no município como: mercearias, supermercados, entre outros. Há também os resíduos públicos originários do sistema de coleta das vias públicas, nas lixeiras e dos órgãos públicos.

Sobre os Resíduos Sólidos de Serviços de Saúde (RSSS), foi informado pelo Secretário Municipal de Saúde que o município de Goiandira possui um convênio com a cidade de Catalão para o recebimento e incineração dos RSSS. Os entulhos da construção civil são transportados e depositados no aterro controla- 
do por terceiros, sendo evidenciada a falta de procedimentos e monitoramentos desses resíduos.

Quanto à geração de resíduos especiais, não foram obtidas informações sobre a existência de coleta diferenciada para pilhas, baterias, lâmpadas, embalagens de agrotóxicos e resíduos eletroeletrônicos. Por esse motivo, aponta-se a necessidade de o município desenvolver programas específicos para essas categorias, evitando maiores problemas ambientais e de saúde pública.

Durante as visitas no aterro municipal foram observados e pontuados alguns aspectos descritos abaixo:

a) Não há controle da entrada e saída de veículos no recinto.

b) Não existe controle da quantidade de resíduos que chegam diariamente no aterro.

c) Não há alojamentos instalados na área.

d) Não há sistema de drenagem de água pluvial instalado no referido local.

e) Não há medidas de proteção de taludes.

f) Não há pátio de compostagem.

g) Não há área para estoque de materiais de qualquer espécie.

h) Não há vigilância da área.

i) Não há usinas de triagem.

j) Toda área é cercada, porém não existe controle de acesso ao local.

k) Não há iluminação externa para realização de possíveis trabalhos noturnos;

1) Possui um galpão que acondiciona os pneus coletados no município, sem nenhuma estratégia de disposição final para tais.

m) Encontra-se no aterro uma quantidade estimada de quinhentas embalagens de agrotóxicos.

n) As valas são abertas sem nenhuma normatização.

o) Os resíduos de construção civil são dispostos na entrada do aterro, sem nenhuma fiscalização e controle.

p) No aterro não existe nenhum tipo de impermeabilização do solo, nem coleta e tratamento do chorume, o que é agravado ainda pelo descarte dos efluentes coletados na área urbana (fossas) e dispostos em uma lagoa dentro do aterro.

q) As margens do aterro são completas de lixo jogado por moradores.

r) Não há uma sistematização quanto à compactação dos resíduos nas valas.

Diante dos apontamentos, o aterro municipal de Goiandira não atende às conformidades físicas e funcionais regulamentadas pela Lei $\mathrm{n}^{\circ} 12.305 / 2010$. A área utilizada para alocação do lixo urbano definiu-se que se trata de um "lixão" e há somente contenção do lixo por uma camada de terra, como mostra a Figura 1. 


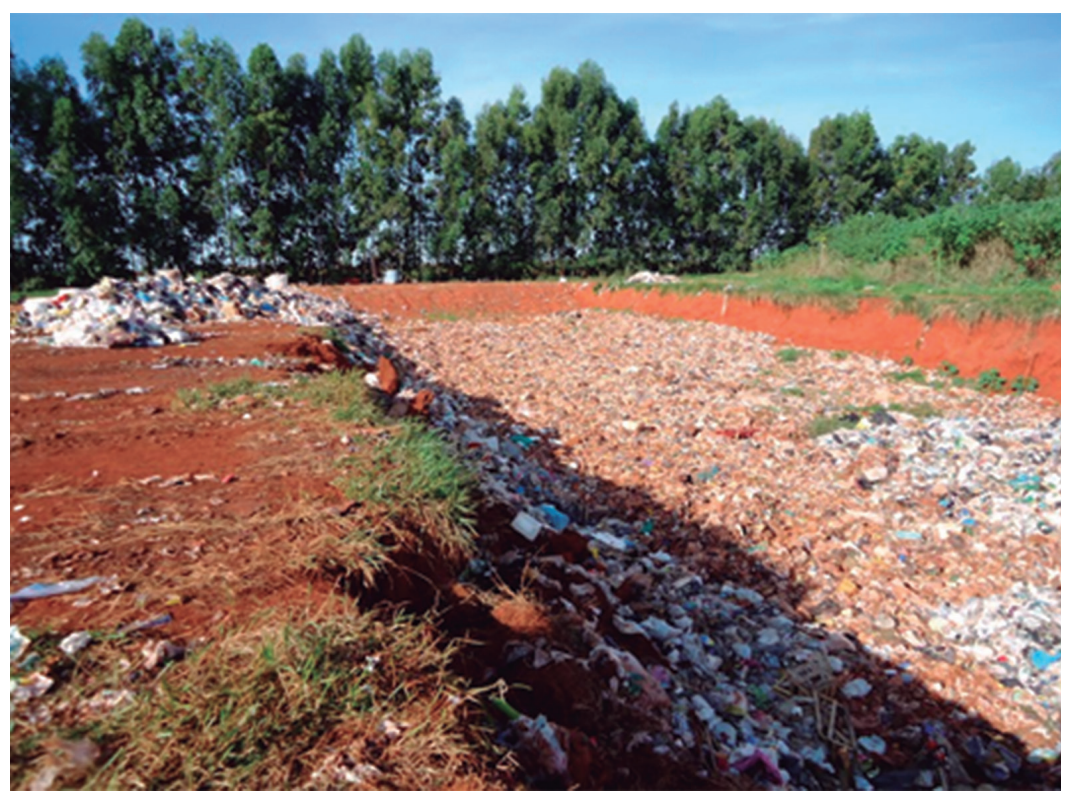

Figura 1. Aterro municipal de Goiandira: valas abertas sem atender a normas e legislações (2015). Crédito: Mayara Cristina Tristão.

Esse sistema minimiza o mau cheiro e o impacto visual, além de diminuir a propagação de insetos e animais. Porém, não há impermeabilização de base, nem sistema de tratamento do chorume ou do biogás. Desse modo, verifica-se a necessidade de intervenção e reabilitação do local, atendendo os requisitos e normas técnicas mínimas vigentes. Esse local funciona como abrigo para animais como urubus, cachorros, gatos, dentre outros, e se torna então o local propício para a proliferação de doenças.

Para o acondicionamento do lixo domiciliar urbano, no município de Goiandira, foram identificadas várias formas de contenção utilizadas pelos moradores, dentre elas, tambores confeccionados pela Secretaria de Infraestrutura e distribuídos pelas vias públicas, sacos plásticos, caixas de papelão etc. Tal fato agrava, sobremaneira, as condições de saúde pública, em virtude da proliferação de vetores transmissores de doenças (moscas, mosquitos ratos, baratas etc.) e do abandono de animais (cães e gatos), além de dificultar a execução dos serviços de coleta (aumento no tempo) e sobrecarregar o trabalho dos coletores.

A coleta e o transporte dos resíduos sólidos domiciliares e comerciais em Goiandira são realizados pela Prefeitura em todas as vias públicas abertas à circulação, como podemos verificar na rota descrita em linhas amarelas na Figura 2. A coleta acontece de segunda a sexta-feira, utilizando um caminhão compactador de $5 \mathrm{~m}^{3}$, com quatro colaboradores 


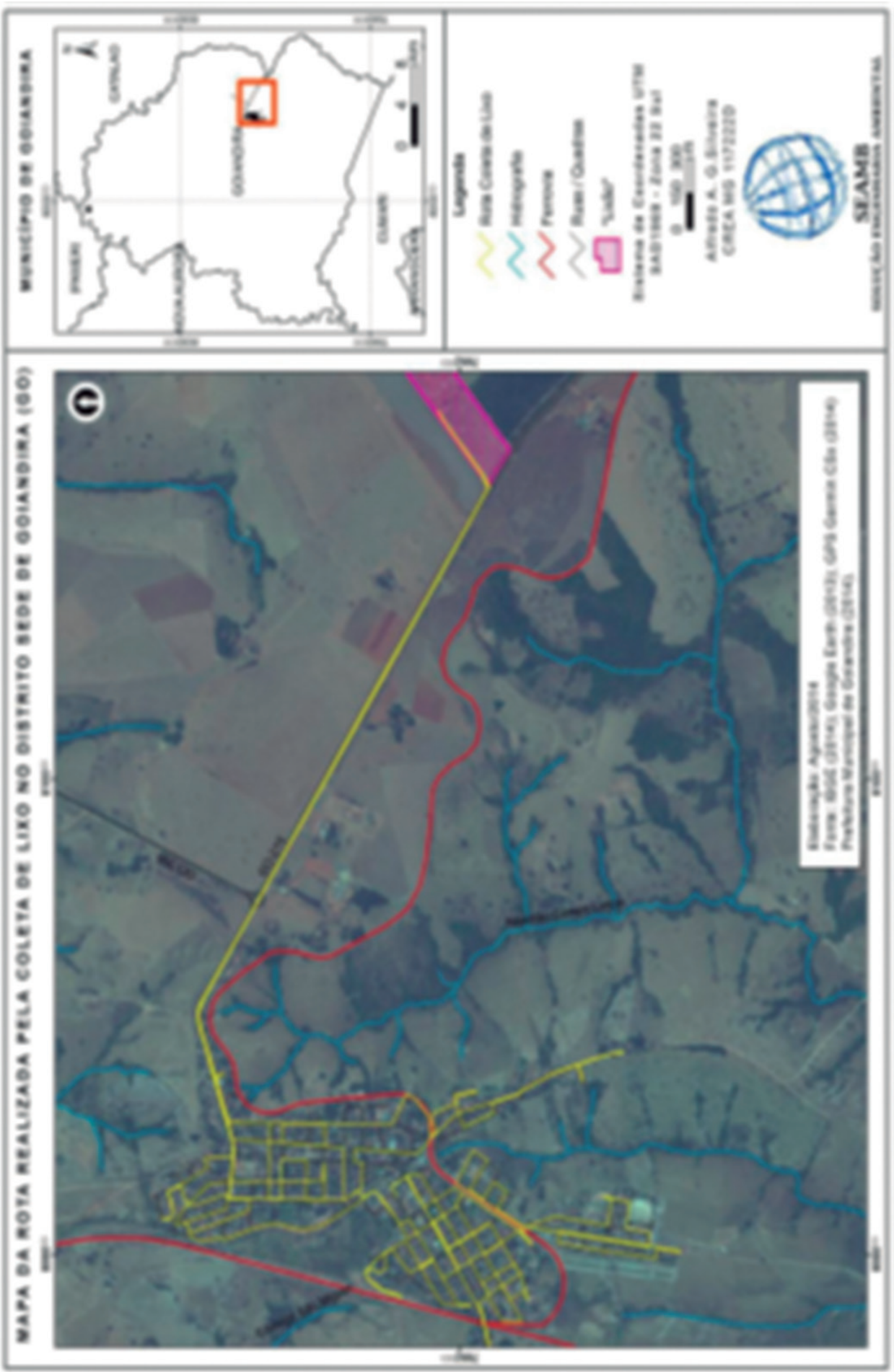

Figura 2. Município de Goiandira-G0: mapa da rota de coleta (2014). Fonte: SEAMB. 
Também é utilizado para o recolhimento dos resíduos, um trator com carreta, responsável pela coleta de papelão e plástico nos comércios, sendo apenas um funcionário designado para condução e recolhimento dos resíduos. Aos sábados é realizada a coleta de resíduos da feira com este mesmo trator. O município não dispõe de uma política para coleta seletiva dos resíduos, contudo existe uma separação dos resíduos recicláveis após a disposição do lixo coletado pelo caminhão no aterro controlado pelo funcionário autônomo. Como não existe uma coleta diferenciada para cada tipo de resíduo, muitos materiais que poderiam ser reaproveitados ou reciclados não atingem essa finalidade.

A partir da caracterização dos resíduos sólidos feita no aterro municipal de Catalão, podemos diagnosticar a quantidade em $\mathrm{kg}$ de cada item gerado por dia de amostragem, como observamos na Tabela 1 .

Tabela 1. Município de Goiandira-G0: amostragens por dia/categoria (2015)

\begin{tabular}{cccccc}
\hline Itens & Amostra l. (Kg) & Amostra 2. $(\mathbf{K g})$ & Amostra 3. $(\mathrm{Kg})$ & Total & $\%$ \\
\hline Plástico & 40 & 6 & 10 & 56 & 0,53 \\
Pet & 100 & 30 & 70 & 200 & 1,91 \\
Metal & 60 & 20 & 40 & 120 & 1,14 \\
Papelão & 140 & 50 & 110 & 300 & 2,86 \\
Caixa de Leite & 10 & 03 & 09 & 22 & 0,21 \\
$\quad$ Pneus & 10 & 0 & 0 & 10 & 0,09 \\
Org/final de & 5.900 & 1.731 & 2.151 & 9.782 & 93,25 \\
esteira & & 1.840 & 2.390 & 10.490 & 100 \\
Total por Dia & 6.260 & & & &
\end{tabular}

Fonte: Pesquisa de campo (2015).

A variação no volume das amostras justifica-se pelos dias das coletas. A primeira amostragem foi realizada na segunda-feira; a segunda, na quarta-feira; e a última, na sexta-feira, o que culminou numa condição esperada: na primeira amostragem, a quantidade de resíduos coletados $6.260 \mathrm{~kg}$ foi bem superior em relação às da segunda e terceira amostragens, respectivamente, $1.840 \mathrm{~kg}$ e 2.390 $\mathrm{kg}$. Tal fato tende a ocorrer devido ao acúmulo de resíduos gerados durante o final de semana, quando não há coleta.

A categoria 'Orgânicos e/ou Final de Esteira' foi a que apresentou maior expressão, sendo 93,34\%, tal proporção pode ser atribuída à ausência da coleta seletiva, o que diminui a quantidade de resíduos viáveis à reciclagem. A segunda categoria, com a maior quantidade de resíduos coletados foi a do 'Papelão', com 
um total de 2,86\%, número que é evidenciado pela coleta exclusiva realizada nos pontos de comércio, sendo estes locais considerados os maiores produtores/ consumidores de papelão.

A produção per capita de resíduos sólidos urbanos de uma comunidade pode ser obtida pela divisão da quantidade total de resíduos coletados pela população atendida (JARDIM et al., 2000). Porém, a massa per capita de resíduos obtida não corresponde exatamente à quantidade gerada por habitante, visto que nesse total estão incluídos resíduos de construção civil, de varrições de rua e de atividades comerciais.

Durante o estudo, também foi evidenciado que o município gera bastante garrafas pet, apesar da diferença em percentagem mostrada no Tabela 1. Essas garrafas poderiam acrescentar a renda familiar de diversas famílias se fossem recicladas, transformando-se em vassouras domésticas, por exemplo. Apenas um (1) pneu foi coletado nesse período, mas durante a análise observacional no Lixão, nota-se o grande número estocado de maneira irregular em frente ao único galpão existente no local (ver Figura 3).

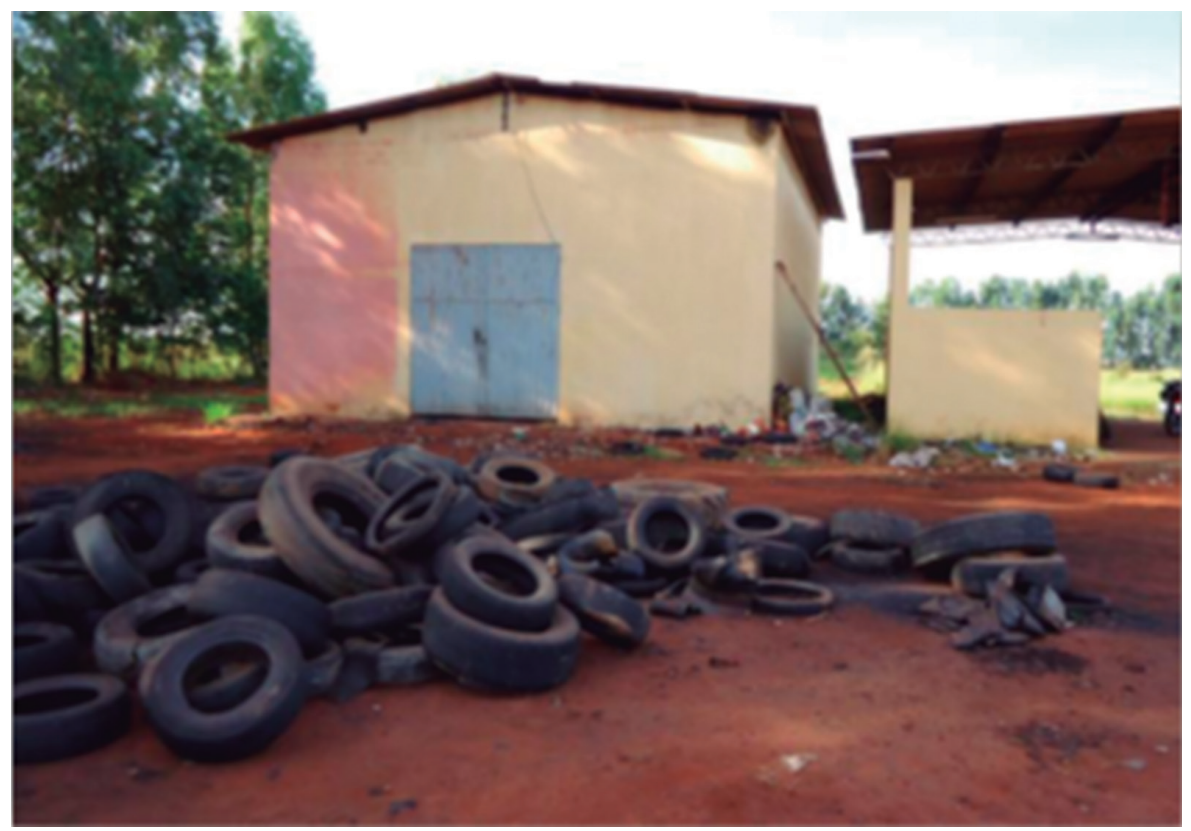

Figura 3. Pneus acondicionados irregularmente na área do aterro.

Problemas sanitários também foram detectados, devido à presença de pombos que usam o local como abrigo. Conforme aponta Nunes (2003), as fezes destes animais podem transmitir doenças, como: salmonelose, Psitacose, Criptococose dentre outras. 


\section{CONCLUSÃO}

A disposição final dos resíduos sólidos no aterro sanitário não ocorre conforme previsto na Lei $\mathrm{n}^{\circ}$ 12.305/2010 que estabelece normas e delimita um tempo para eliminação dos lixões nos municípios brasileiros. Assim, Goiandira está inserida entre os municípios que ainda não possuem aterro sanitário, sendo que os resíduos são depositados em lixão, sem monitoramento da quantidade de resíduos depositados diariamente.

O cenário atual dos aspectos administrativos, operacionais e estruturais da prestação dos serviços retratados pelo diagnóstico situacional alcançou níveis pouco satisfatórios na maioria de seus indicadores, o que revela carências e deficiências cuja superação deve ser objeto de implantação de programas de controle e de monitoramento.

Contudo, evidenciamos a importância de gerenciar os resíduos sólidos urbanos do município de forma integrada e articulada. Perfazendo um conjunto de ações operacionais, financeiras e de planejamento da Gestão Pública. Para construção e efetivação do planejado, são necessários critérios sanitários, ambientais e econômicos para coletar, tratar, aproveitar e dispor adequadamente os resíduos sólidos de uma cidade. A educação ambiental deve ser inserida como estratégia, sendo de fundamental importância para se alcançar o objetivo, pois a conscientização da população contribui diretamente para o sucesso das campanhas.

Sendo assim, o município de Goiandira necessita de uma política ambiental e social eficaz, tendo em vista a criação de um aterro sanitário para atender a Lei $\mathrm{n}^{\circ}$ 12.305/2010. A caracterização dos Resíduos Sólidos Urbanos do município foi apenas o primeiro passo, de inúmeros, para a resolução da problemática existente em municípios de pequeno porte.

\section{REFERÊNCIAS}

ANA- Agência Nacional de Águas. Diagnóstico da bacia hidrográfica do rio Paranaíba. Brasília: Agência Nacional de Águas, 2011. 1130 p.

ASSOCIAÇÃO BRASILEIRA DE NORMAS TÉCNICAS. NBR 10004: Resíduos sólidos - Classificação. Rio de Janeiro: ABNT, 2004.

NBR 10004: Resíduos sólidos - Classificação. Rio de Janeiro: ABNT, 2004.

NBR 11174: Armazenamento de resíduos classe II-A, não inertes, e classe II-B, inertes - Procedimentos. Rio de Janeiro: ABNT, 1990.

NBR 12245: Armazenamento de resíduos sólidos perigosos - Procedimentos.

Rio de Janeiro: ABNT, 1992.

NBR 12807: Resíduos de serviço de saúde - Terminologia. Rio de Janeiro:

ABNT, 1993. 
NBR 12808: Resíduos de serviço de saúde - Classificação. Rio de Janeiro: ABNT, 1993.

. NBR 13.221: Transporte terrestre de resíduos; Rio de Janeiro: ABNT, 2003. 1994. . NBR 13221: Transporte de resíduos - Procedimento. Rio de Janeiro: ABNT,

. NBR 13896: Aterros de resíduos não perigosos - Critérios para projeto, implantação e operação. Rio de Janeiro: ABNT 1997.

. NBR 7039: Pilhas e acumuladores elétricos - Terminologia. Rio de Janeiro: ABNT, 1987. ABNT, 1989.

. NBR 7501: Transporte de produtos perigosos - Terminologia. Rio de Janeiro:

- NBR 8419: Apresentação de projetos de aterros sanitários de resíduos sólidos urbanos. Rio de Janeiro: ABNT, 1992.

BAASCH, S. S. N.; DUARTE, M. S. Produção per capita de lixo domiciliar no município de Florianópolis. Florianópolis-SC: ENS;UFSC, 1995.

BRASIL. Constituição da República Federativa do Brasil de 1988.

BRASIL. Lei Federal no 11.445, de 5 de Janeiro de 2007. Estabelece diretrizes nacionais para o saneamento básico; altera as Leis nos 6.766, de 19 de dezembro de 1979, 8.036, de 11 de maio de 1990, 8.666, de 21 de junho de 1993, 8.987, de 13 de fevereiro de 1995; revoga a Lei no 6.528, de 11 de maio de 1978; e dá outras providências. Disponível em: <http://www.planalto.gov.br/ccivil_03/_ato2007 2010/2007/lei/111445. htm>. Acesso em: 15 fev. 2015.

BRASIL. Lei Federal $\mathbf{n}^{\circ}$ 12.305, de 2 de agosto de 2010. Institui a Política Nacional de Resíduos Sólidos; altera a Lei no 9.605, de 12 de fevereiro de 1998; e dá outras providências. Disponível em: <http://www.planalto.gov.br/ccivil_03/_Ato20072010/2010/Lei/L12305.htm>. Acesso em: 15 fev. 2015.

CAMPOS, H. K. T. et al. Curso: modelo de gestão integrada dos resíduos sólidos urbanos. A Geração de resíduos no Brasil e os problemas associados. Rio de Janeiro: 1999. $173 \mathrm{p}$.

CENTRO TECNOLÓGICO DE ENGENHARIA; SISTEMA NATURAE. Estudo integrado da bacia hidrográfica do rio Veríssimo.Goiânia, 2006. 389 p. (v. 1, relatório disponível em CD-Rom).

CONSELHO NACIONAL DO MEIO AMBIENTE. Resolução n ${ }^{\circ} 05$ de 5 de agosto de 1993. Dispõe sobre o plano de gerenciamento, tratamento e destinação final de resíduos sólidos de serviços de saúde, portos, aeroportos, terminais rodoviários e ferroviários, 1993. Disponível em: <http://www.mma.gov.br/port/conama/res/res93/res0593.html>. Acesso em: 15 fev. 2015.

D'ALMEIDA, M. L. O.; VILHENA A. Lixo municipal: manual de gerenciamento integrado. 2. ed. São Paulo: IPT; CEMPRE, 2000.

EPE. Avaliação ambiental integrada dos aproveitamentos hidrelétricos da bacia hidrográfica do rio Paranaíba. Empresa de Pesquisa Energética. [S. 1.], 2006. 
FERREIRA, O. M.; SILVA, K. A. Diagnóstico da disposição final dos resíduos sólidos no estado de Goiás. Estudos, Goiânia, v. 38, n. 2, p. 227-233, abr./jun. 2011.

FERREIRA, O. M. (Coord.). Diagnóstico do monitoramento dos projetos de disposição do lixo urbano dos municípios goianos. Agência Goiana de Meio Ambiente, 2006.

GOIÁS. Lei Estadual no 14.248, de 29 de julho de 2002. Dispõe sobre a Política Estadual de Resíduos Sólidos e dá outras providências. Disponível em: <http://www. gabinetecivil.goias.gov.br/leis_ordinarias/2002/lei_14248>. Acesso em: 15 fev. 2015. IBGE - Instituto Brasileiro de Geografia e Estatística. Anuários estatísticos do Brasil. Rio de Janeiro: IBGE, 1989, 2004.

IBGE - Instituto Brasileiro de Geografia e Estatística. Disponível em: <http://www.ibge. gov.br/home/presidencia/noticias/21052004biomashtml.shtm>. Acesso em: 11 abr. 2015. . Banco de Dados do Município de Goiandira. Disponível em: <http://www. cidades.ibge.gov.br/painel/historico.php?lang=\&codmun=520850\&search=goias/goiandi ralinfograficos:-historico>. Acesso em: 11 abr. 2015.

JARDIM, N. S. et al. Gerenciamento integrado do lixo municipal. In: D'ALMEIDA, M. L. O.; VILHENA, A. (Coord.). Lixo municipal: manual de gerenciamento integrado. 2. ed. São Paulo: Institutode Pesquisas Tecnológicas - IPT/ Compromisso Empresarial para Reciclagem - CEMPRE, 2000, p. 3-25.

NUNES, V. F. P. Pombos urbanos: o desafio de controle. Biológico, v. 65, n. 1/2, p. 8992, 2003.

OJIMA, R. Análise comparativa da dispersão urbana nas aglomerações urbanas brasileiras: elementos teóricos e metodológicos para o planejamento urbano e ambiental. Tese (Doutorado) - Instituto de Filosofia e Ciências Humanas, Universidade Estadual de Campinas, 2007.

PORTO-GONÇALVES, C. W. A globalização da natureza e a natureza da globalização. Rio de Janeiro: Civilização Brasileira, 2006.

PRADO, M. L. et. al. Caracterização física dos resíduos sólidos domésticos do município de Caldas Novas-GO. Artigo técnico desenvolvido para conclusão do curso de Engenharia Ambiental da Universidade Católica de Goiás. 2004. 22 p.

ZANTA, V. M.; FERREIRA, C. F. A. Capítulo 1 - Gerenciamento integrado de tesíduos sólidos urbanos. In: CASTILHOS JR., A. B. (Coord.). Resíduos sólidos urbanos: aterro sustentável para municípios de pequeno porte. Rio de Janeiro: ABES, RIMA, 2003. 280 p. 